\title{
Thermal Analysis of Dual Brake System
}

\author{
Yuvaperiyasamy.M, Hariganesh.V \\ ME-THERMAL ENGINEERING RVS College of Engineering and Technology Coimbatore, India \\ Assistant Professor, Mechanical engineering RVS College of Engineering and Technology Coimbatore, India
}

\begin{abstract}
In our project it's constructed in FEA approach to solving a transient analysis for the thermo elastic contact problem of the Dual brakes [Corp-Ashock Leyland] with heat generation is performed varying load. To analyze the thermo elastic phenomenon occurring in the Dual brakes, the occupied heat conduction and elastic equations are solved with contact problems. The numerical simulation for the thermo elastic behavior of Dual brake is obtained in the repeated brake condition. The computational results are presented for the distribution of heat flux and temperature distribution an alysis on each friction surface between the contacting bodies. The influence of the material properties on the thermo elastic behaviors is investigated to facilitate the conceptual design of the Dual brake system. Based on these numerical results, carbon-carbon composites materials are consumed. Brakes simulating varied speed ratio. When brake applied, each wheel of the vehicle builds-up a certain braking force. The system it's taken from 6wheeler analyzed. Brake shoe assembly is completely reengineering modeled using Pro/E and the analysis of the brake shoe assembly is carried out in Ansys. The results are analyzed.
\end{abstract}

\section{Introduction}

A brake is a device by means of which artificial frictional resistance is applied to moving machine member, in order to stop the motion of a machine. In the process of performing this function, the brakes absorb either kinetic energy of the moving member or the potential energy given up by objects being lowered by hoists, elevators etc. The energy absorbed by brakes is dissipated in the form of heat. This heat is dissipated in the surrounding atmosphere.

\subsection{B raking Requirements}

The brakes must be strong enough to stop the vehicle with in a minimum distance in an emergency.

$>$ The driver must have proper control over the vehicle during braking and vehicle must not skid.

$>$ The brakes must have well anti fade characteristics i.e. their effectiveness should not decrease with constant prolonged application.

The brakes should have good anti wear properties.

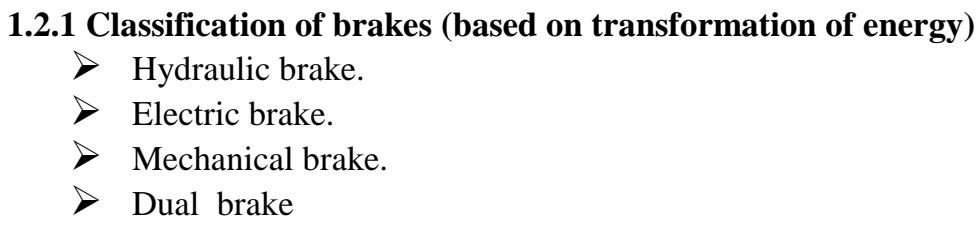

1.2.1 Classification of brakes (based on transformation of energy)

$>$ Hydraulic brake.

Electric brake.

$>$ Mechanical brake.

$>$ Dual brake

\subsubsection{Dual brake}

A Dual brake consists of a cast iron Dual bolted to the wheel hub and a stationary housing called caliper. The caliper is connected to some stationary part of the vehicle like the axle casing or the stub axle as is cast in two parts each part containing a piston. In between each piston and the Dual there is a friction pad held in position by retaining pins, spring plates etc. passages are drilled in the caliper for the fluid to enter or leave each housing. The passages are also connected to another one for bleeding. Each cylinder contains rubber-sealing ring between the cylinder and piston. A schematic diagram is shown in the figure 1.1 . 


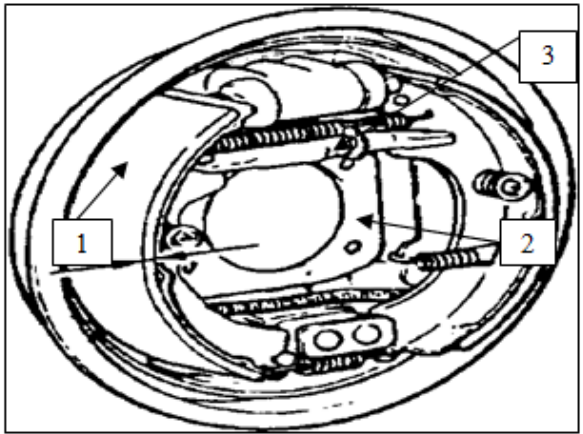

Fig 1.1 Dual brake system

The main components of the Dual brake are:

1. The Brake Pads

2. The Caliper which contains the piston

3. The Rotor, which is mounted to the hub.

\subsection{Objectives of the project}

The present investigation is aimed to study:

1. The given Dual brake rotor of its stability and rigidity (for this Thermal analysis and coupled structural analysis is carried out on a given dual b $\mathrm{r}$ a k e rotor.

2. Best combination of parameters of Dual brake rotor like Flange width, Wall thickness and material there by a best combination is suggested.

\section{Methodology}

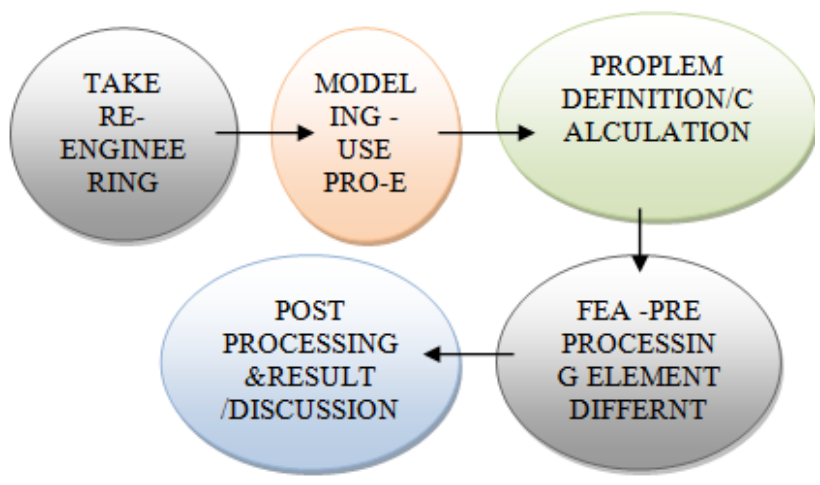

Fig 2.0 Methodology

\section{Finite Element Analysis}

The finite element method is numerical analysis technique for obtaining approximate solutions to a wide variety of engineering problems. Because of its diversity and flexibility as an analysis tool, it is receiving much attention in almost every industry. In more and more engineering situations today, we find that it is necessary to obtain approximate solutions to problem rather than exact closed form solution.

It is not possible to obtain analytical mathematical solutions for many engineering problems. An analytical solutions is a mathematical expression that gives the values of the desired unknown quantity at any location in the body, as consequence it is valid for infinite number of location in the body. For problems involving complex material properties and boundary conditions, the engineer resorts to numerical methods that provide approximate, but acceptable solutions.

\subsection{Procedure for ANSYS analysis}

Static analysis is used to determine the displacements stresses, stains and forces in structures or components due to loads that do not induce significant inertia and damping effects. Steady loading in response conditions are assumed. A static analysis can be either linear or non linear. In our present work we consider linear static analysis. The procedure for static analysis consists of these main steps 


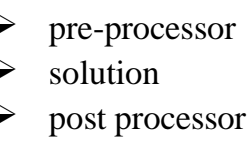

\section{2 steps followed}

In this step we define the analysis type and options, apply loads and initiate the finite element solution. This involves three phases:

Pre-processor phase

Solution phase

Post-processor phase

\subsection{Pre-processor:}

Pre processor has been developed so that the same program is available on micro, mini, super-mini and mainframe computer system. This slows easy transfer of models one system to other.

\subsection{Solution:}

The solution phase deals with the solution of the problem according to the problem definitions. All the tedious work of formulating and assembling of matrices are done by the computer and finally displacements are stress values are given as output. Some of the capabilities of the ANSYS are linear static analysis, non linear static analysis, transient dynamic analysis, etc.

\subsection{Post- processor:}

It is a powerful user- friendly post- processing program using interactive colour graphics. It has extensive plotting features for displaying the results obtained from the finite element analysis.

\subsection{Dual Brake Calculation:}

\section{Dual Barke Calculations}

\section{Given data:}

Velocity of the vehicle $=70 \mathrm{~m} . \mathrm{p} \cdot \mathrm{h}=112.65408 \mathrm{kmph}=$ $32.2928 \mathrm{~m} / \mathrm{s}$

Time for stopping the vehicle $=4$ seconds

Mass of the vehicle $=1400 \mathrm{~kg}$

Step-1:

Kinetic energy $($ K.E $)=1 / 2 * \mathrm{~m} * \mathrm{v} 2$

$=1 / 2 * 1400 * 31.29282$

$=685467.5323$ Joules

Step-2

The total kinetic energy=The heat generated

$\mathrm{Qg}=685467.5323$ Joules

Step-3

The area of rubbing faces

$\mathrm{A}=\Pi^{*}(0.1802-0.10362)$

$=0.068069$

\section{Step-4}

Heat Flux $=$ Heat Generated $/$ Second /rubbing area

$=685467.5323 / 4 / 0.068069$

$=2517546.652 \mathrm{Watts} / \mathrm{m} 2$

Step-5

Braking Area

For outer shoe Area (A1)

$=100 * 0.108 * 0.2 *(\pi / 180)$

$=0.037 \mathrm{~m}^{2}$

Area of inner shoe (A2)

$=100 * 0.10 * 0.055 *(\pi / 180)$

$=0.00959 \mathrm{~m}^{2}$

$\mathrm{A} 2 / \mathrm{A} 1=0.25$

Step-6 


\section{Force Calculation}

Braking force $=\left(\mathrm{M}_{\mathrm{n}}-\mathrm{M}_{\mathrm{f}}\right) / \mathrm{C}$

(From PSG data book)

$\mathrm{M}_{\mathrm{n}}$ - moment of normal force.

$\mathrm{M}_{\mathrm{f}}$-moment of friction force.

$\mathrm{C}$ - distance of force acting

$\mathrm{M}_{\mathrm{n}}=1769.1 \mathrm{Nm}, \mathrm{M}_{\mathrm{f}}=1058.9 \mathrm{Nm}$

Braking force $=2840 \mathrm{~N}$

\subsection{Force \& Stiffness Calculation}

Reaction pressure $=400000 \mathrm{~N} / \mathrm{m}^{2}$

(From PSG data book)

Spring stiffness is calculated using spring testing machine.

Spring force $=40 \mathrm{~N}$

Stiffness of the spring $=15.8 \mathrm{~N} / \mathrm{mm}$

\subsection{Total frictional force calculation:}

For modified braking system

Frictional force on front wheel $\left(\mathrm{TF}_{\mathrm{F}}=16380 \mathrm{~N}\right.$

Frictional force on rear wheel $\left(\mathrm{TF}_{\mathrm{R}}\right)=159553 \mathrm{~N}$

Retardation of the vehicle $(\mathrm{f})=12.28 \mathrm{~m} / \mathrm{s}^{2}$

For conventional braking system

Frictional force on front wheel $\left(\mathrm{TF}_{\mathrm{F}}\right)=16380 \mathrm{~N}$

Frictional force on rear wheel $\left(\mathrm{TF}_{\mathrm{R}}\right)=137493 \mathrm{~N}$

Retardation of the vehicle $\mathrm{f}=10.87 \mathrm{~m} / \mathrm{s}^{2}$

\subsection{Skid distance}

$\mathrm{S}=\mathrm{V}^{2} /(2 * \mathrm{f})$

$\mathrm{V}=70 \mathrm{~km} / \mathrm{hr}$

i) For modified system $\quad=7.84 \mathrm{~m}$

ii) For conventional system $=8.86 \mathrm{~m}$

\subsection{Heat generated in the rear drum}

$$
\mathrm{Q}=\text { braking force } * \text { distance moved }
$$

i) For modified system $\quad=22.270 \mathrm{KJ}$

ii) For conventional system $=25.162 \mathrm{KJ}$

\subsection{Braking time}

Braking time (t) from the relationship

i) For modified system $\quad=1.16 \mathrm{sec}$

ii) For conventional system $=1.29 \mathrm{sec}$

$$
\mathrm{S}=(\mathrm{u} * \mathrm{t})+(1 / 2) *\left(\mathrm{f} * \mathrm{t}^{2}\right)
$$

5.1 The Material properties of Cast Iron:

\section{Material Properties}

Thermal coefficient of expansion $=1.7039 \mathrm{e}-5 /{ }^{\circ} \mathrm{C}$

Thermal conductivity $(\mathrm{K})=54.0 \mathrm{~W} / \mathrm{m} \mathrm{k}$

Specific heat $(\mathrm{Cp})=586.0 \mathrm{~J} / \mathrm{Kg} \mathrm{k}$

Density of Cast Iron $=7100 \mathrm{~kg} / \mathrm{m} 3$

Young's Modulus $(\mathrm{E})=125 \mathrm{e} \mathrm{N} / \mathrm{m} 2$

Poisson's ratio $(\mathrm{v})=0.25$

5.2 The Material properties of Stainless steel:

Thermal coefficient of expansion $=1.72 \mathrm{e}-5 /{ }^{\circ} \mathrm{C}$

Thermal conductivity $(\mathrm{K})=16.2 \mathrm{~W} / \mathrm{m} \mathrm{k}$

Specific heat $(\mathrm{Cp})=500 \mathrm{~J} / \mathrm{Kg} \mathrm{k}$

Density of Cast Iron $=7860 \mathrm{~kg} / \mathrm{m} 3$

Young's Modulus $(\mathrm{E})=193 \mathrm{e} \mathrm{N} / \mathrm{m} 2$

Poisson's ratio $(\mathrm{v})=0.29$ 
5.3 The Material properties of Aluminum:

Thermal coefficient of expansion $=2.3 \mathrm{e}-5 /{ }^{\circ} \mathrm{C}$

Thermal conductivity $(\mathrm{K})=155 \mathrm{~W} / \mathrm{m} \mathrm{k}$

Specific heat $(\mathrm{Cp})=880 \mathrm{~J} / \mathrm{Kg} \mathrm{k}$

Density of Cast Iron $=2800 \mathrm{~kg} / \mathrm{m} 3$

Young's Modulus $(\mathrm{E})=72.4 \mathrm{e} \mathrm{N} / \mathrm{m} 2$

Poisson's ratio $(\mathrm{v})=0.33$

5.4 The Material properties of Asbestos:

Thermal coefficient of expansion $=0.4 \mathrm{e}-5 /{ }^{\circ} \mathrm{C}$

Thermal conductivity $(\mathrm{K})=0.1105 \mathrm{~W} / \mathrm{m} \mathrm{k}$

Specific heat $(\mathrm{Cp})=816 \mathrm{~J} / \mathrm{Kg} \mathrm{k}$

Density of Cast Iron $=2500 \mathrm{~kg} / \mathrm{m} 3$

Young's Modulus $(\mathrm{E})=1.86 \mathrm{e} \mathrm{N} / \mathrm{m} 2$

Poisson's ratio $(\mathrm{v})=0.31$

\section{Thermal Analysis}

A Thermal analysis calculates the temperature distribution and related thermal quantities in brake Dual. Typical thermal quantities are:

The temperature distribution

1. The amount of heat lost or gained

2. Thermal fluxes

\subsection{Types of thermal analysis:}

A steady state thermal analysis determines the temperature distribution and other thermal quantities under steady state loading conditions. A steady state loading condition is a situation where heat storage effects varying over a period of time can be ignored.

A transient thermal analysis determines the temperature distribution and other thermal quantities under conditions that varying over a period of time

\subsection{Planning the analysis:}

In this step a compromise between the computer time and accuracy of the analysis is made. The various parameters set in analysis are given below:

Thermal modeling

$>$ Analysis type - thermal h-method.

$>$ Steady state or Transient? Transient

$>$ Thermal or Structural? Thermal

$>$ Properties of the material? Isotropic

$>$ Objective of analysis- to find out the temperature distribution in the brake Dual $\mathrm{w} h$ e $\mathrm{n}$ the process of braking is done.

Units- SI

Thermal Transient Analysis In Varies Components

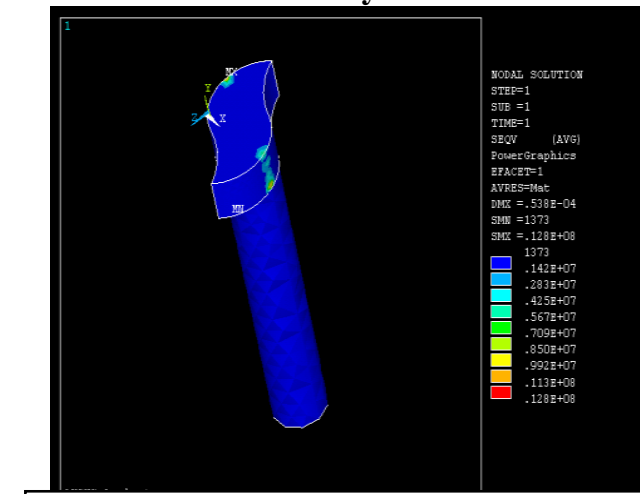

Fig 6.3.1.Cam shaft analysis -Thermal

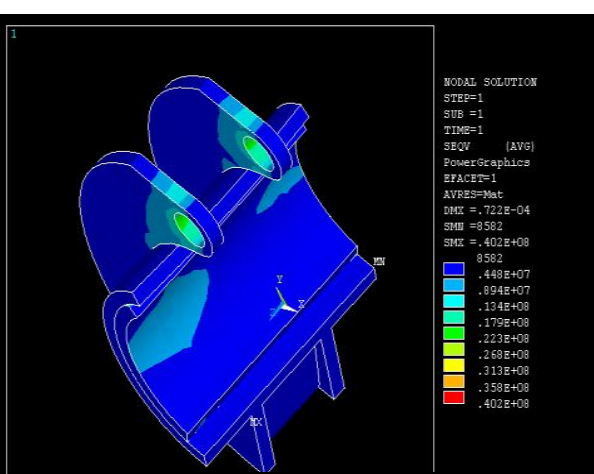

Fig 6.3.4 Brake Drum -Thermal 


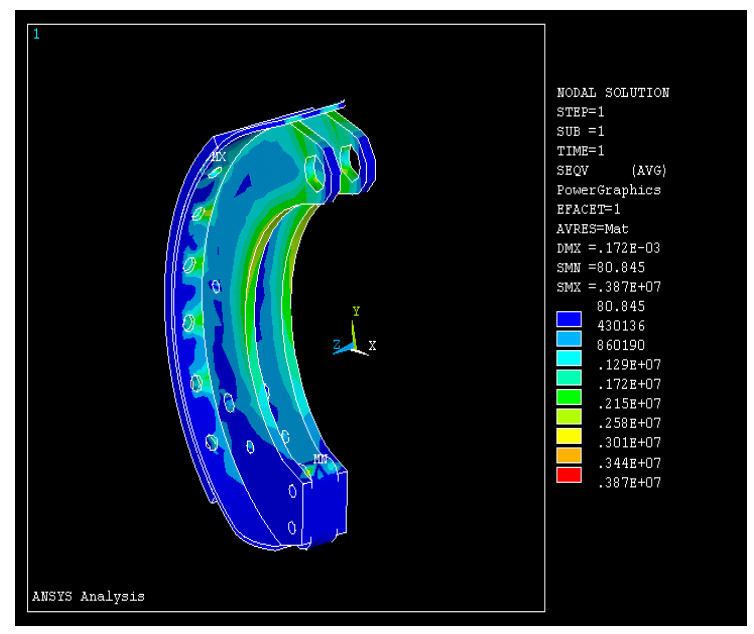

Fig 6.3.2 brake shoe-RH side

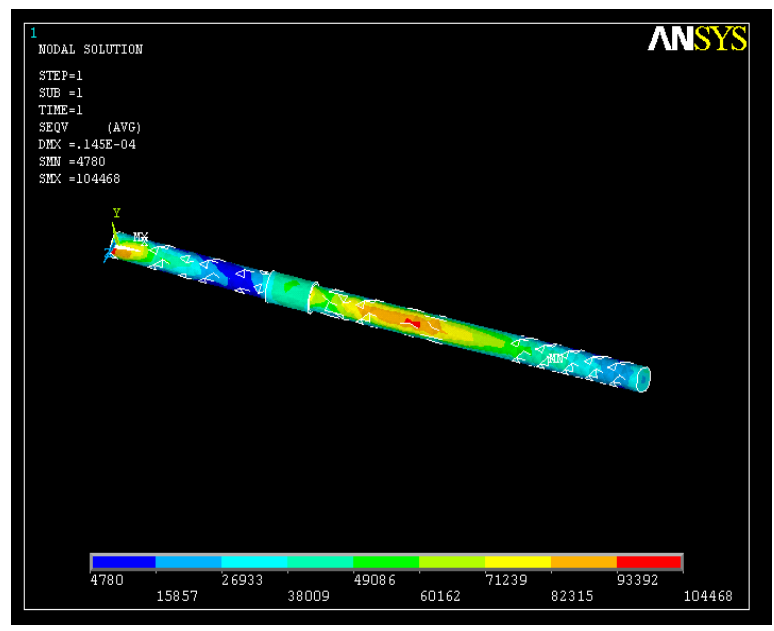

Fig 6.5.5 Braking shaft -centre

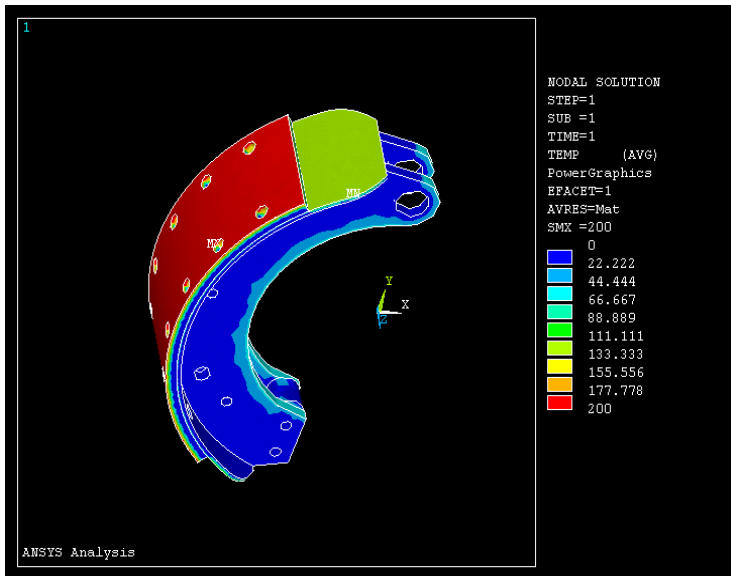

Fig 6.3.3 Brake shoe -LH side

\section{Summery}

In this project, the traditional air brake system of Ashokleyland is modeled and analyzed. Stress distribution is found to be uneven; brake assembly is redesigned and analyzed, through Ansys a FEA package. The Ansys results shown in the following table gives clear idea that the redesigned model is better than the existing model. With the redesigned model, Friction in Dual brake, kitting distance and the brake lining material life is increase.

\section{Future Scope Of The Project} ANSYS.

In the present work investigation of Thermal analysis of dual brake is analyzed by FEA package

As a future work, a complicated model of dual brake can be taken and there by forced convection is to be considered in the analysis.

The analysis is still becomes complicated by considering variable thermal conductivity, variable specific heat non uniform deceleration of the vehicle. This can be considered for the future work.

\section{Reference}

[1]. LIN , J. -Y. AND CHEN, H. -T. Radial Axis symmetric Transient Heat Conduction in Composite Hollow Cylinders with Variable Thermal Conductivity, vol. 10, page 2- 33, (1992).

[2]. COOK, R. D. Concept and Applications of Finite Element Analysis, Wiley, Canada, (1981)

[3]. WANG, H. -C. AND BANERJEE, P. K.. Generalized Axis symmetric Elastodynamic Analysis by Boundary Element Method, vol. 30, page 115-131, (1990).

[4]. FlOQUET, A. AND DUBOURG, M.-C. Non axis symmetric effects for three dimensional Analyses of a Brake, ASME J. Tribology, vol. 116, page 401-407, (1994).

[5]. BEEKER, A.A. The Boundary Element Method in Engineering, McGraw-Hill, New York, (1992). 
[6]. ZIENKIEWICZ, O. C. The Finite Element method, McGraw-Hill, New York, (1977).

[7]. AKIN, J. E. Application and Implementation of Finite Element Methods, Academic Press, Orlando, FL, page 318-323, (1982).

[8]. DOW, T. A. AND BURTON, R. A. Thermo elastic Instability of Sliding Contact in the absence of Wear, Wear, vol. 19, page 315$328,(1972)$

[9]. BARBER, J. R. Contact Problems Involving a Cooled Punch, J. Elasticity, vol. 8, page 409- 423, (1978).

[10]. 10. KENNEDY, F. E., COLIN, F. FLOQUET, A. AND GLOVSKY, R. Improved Techniques for Finite Element Analysis of Sliding Surface Temperatures. Westbury House page 138-150, (1984). 